\title{
Editorial
}

\section{How transoesophageal echocardiography can assist cardiac surgery in adults}

After its development and clinical application in the early 1980s transoesophageal echocardiography was rapidly recognised as providing a unique perspective from which to view the heart. ${ }^{12}$ Transoesophageal echocardiography is now widely applied in cardiology and is particularly useful in cardiac surgery, allowing continuous intraoperative monitoring without transgressing the sterile field. ${ }^{3-5}$ In addition, in the early postoperative period traditional transthoracic imaging is often unsatisfactory for various reasons including the presence of air and tubes in the mediastinum. Transoesophageal echocardiography can resolve clinical problems encountered in adult and paediatric cardiac surgery. Its applications in paediatric surgery are described by Weintraub et al. ${ }^{6}$

\section{General applications}

During routine operations for myocardial revascularisation, transoesophageal echocardiography gives a noninvasive measure of global ventricular function and it can identify regional wall motion abnormalities as possible markers of hypoperfusion both before and immediately after bypass. ${ }^{78}$ The question whether transoesophageal echocardiography should be used in all revascularisation procedures is unresolved. ${ }^{9}$ Though cardiac output and other haemodynamic data can be derived from transoesophageal echocardiography most cardiac surgical groups continue to rely on thermodilution techniques. ${ }^{10}$ Intracardiac air can be visualised easily and de-airing can be continued until transoesophageal echocardiography no longer detects microbubbles. ${ }^{112}$ The relation between embolisation of microbubbles and neuropsychological outcome is not clearly defined. Nevertheless, neuropsychological deficit after' cardiac surgery ${ }^{13}$ is sufficiently common to justify every effort to reduce intraoperative air embolism. Intra-aortic balloon pump insertion can be guided by transoesophageal echocardiography, allowing visualisation of the descending aorta to detect severe atheroma and avoid potential complications. ${ }^{14}$ Transoesophageal echocardiography is the best method of imaging the heart in the early postoperative period. It aids not only the diagnosis of tamponade, but also the diagnosis of other causes of postoperative hypotension ${ }^{15} 16$ and in some situations, such as suspected atypical tamponade, may prompt or even spare a patient repeat thoracotomy. ${ }^{17}$ Daily transoesophageal echocardiography has been used to monitor the recovery of myocardial function in patients who needed assist devices after cardiotomy. The results were used to predict successful weaning from such devices. ${ }^{1819}$

\section{Aortic surgery}

The increasing number of older patients with severe atheromatous disease has focused research interest on the rational management of severe atheroma of the ascending aorta and aortic arch and the attendant risk of neurological complications resulting from potential intraoperative embolisation. ${ }^{20-22}$ Simple palpation of the aorta at operation underestimates the degree of disease ${ }^{2023}$ and therefore intraoperative imaging provides unique information, which in many patients may alter the conduct of the operation. ${ }^{23}$ There is, however, some doubt whether transoesophageal echocardiography is as sensitive in detecting atheroma of the ascending aorta as direct imaging with an epivascular probe. ${ }^{24}$ Though the correct approach to such patients is not yet clear this new information has stimulated some to apply radical surgical approaches to the severely diseased ascending aorta in an attempt to reduce the incidence of neurological complications. These approaches include its prosthetic replacement ${ }^{23}$ or the direct removal of pedunculated atheromas, ${ }^{21} 22$ which have been shown to have a high embolic potential.

Transoesophageal echocardiography is a safe, accurate, and rapid method of diagnosing aortic dissection..$^{25}$ It has several clear advantages over other imaging techniques and can be used at the bedside to allow emergency surgery to proceed expeditiously. ${ }^{26}$ It can show the precise site of the intimal tear and also give functional data on aortic regurgitation and flow within the false lumen to guide surgical intervention. ${ }^{27}$ Biplane and omniplane probes and other technical refinements have also improved the visualisation of the ascending aorta and have increased specificity. ${ }^{26}$ During surgical repair, transoesophageal echocardiography can be used to confirm satisfactory retrograde flow to the great vessels after institution of cardiopulmonary bypass and aortic valve competence after resuspension. This allows prompt surgical revision if significant aortic regurgitation persists. ${ }^{27}$

\section{Valve surgery}

It might be anticipated that the accuracy of transoesophageal echocardiography in the assessment of valve dysfunction could improve strategies in valve surgery. Currently the role of aortic valve repair is limited, though assessment of lesser degrees of aortic valve regurgitation may dictate alteration in the technique of myocardial preservation. Transoesophageal echocardiography gives excellent images of the structures around the aortic root and the technique may be of particular value in the surgery of aortic endocarditis, both in identifying the sites of abscess cavities ${ }^{2829}$ and intracardiac fistulas ${ }^{29}$ and in confirming surgical closure. It also allows homograft sizing and confirmation of satisfactory function of the homograft or prosthetic valve after bypass and gives useful data during pulmonary autograft aortic valve replacement. ${ }^{30}$

The potential role for transoesophageal echocardiography is greater in mitral valve surgery. The anatomy of function and dysfunction of the mitral valve can be clearly defined by transoesophageal echocardiography, particularly in mitral regurgitation, where satisfactory valve repair gives the best short and long term results and decisions made at the time of operation may affect both early and late survival and the need for reoperation..$^{31-36}$ Pre-bypass imaging can prompt or discourage mitral valve surgery ${ }^{33} 34$ and unsatisfactory post-bypass images can lead to further surgical intervention to repair or replace the mitral valve in up to $10 \%$ of cases. 
Furthermore, residual mitral regurgitation detected by transoesophageal echocardiography has been shown to predict poor early and late outcomes. ${ }^{33} 34$ In hypertrophic obstructive cardiomyopathy, a related but different area of surgery, transoesophageal echocardiography has been useful in intraoperative assessment, particularly for assessing the relative importance of muscular septal hypertrophy and systolic anterior motion of the mitral valve leaflet in left ventricular outflow tract obstruction, ${ }^{35}{ }^{36}$ which dictates whether the patient needs septal myectomy alone or additional mitral valve surgery.

\section{Limitations and reservations}

There are reservations about the widespread use of transoesophageal echocardiography as an intraoperative aid to monitoring. It is expensive and complex. Until now surgeons and anaesthetists have had little or no training in basic ultrasound techniques. Overall supervision by experienced observers is required, at least initially, to maximise the potential benefits to patient care. The realisation by surgeons and anaesthetists that a better understanding of the basic principles of ultrasound and Doppler would facilitate the expanding use of these techniques prompted a recent review. ${ }^{37}$ In addition, the effects of prolonged intraoperative oesophageal intubation with synchronous endotracheal intubation on oesophageal and pharyngeal function has not been fully assessed. The imaging of certain structures is still suboptimal. The apex of the left ventricle, the right ventricular outflow tract, and the portion of the ascending aorta anterior to the trachea are the principal areas where satisfactory images are often unobtainable. This will improve as biplane and multiplane imaging probes develop.

Transoesophageal echocardiography has already been widely used both intraoperatively and postoperatively in cardiac surgery patients. It provides new information not previously available to surgeons and anaesthetists that assists decision making. We urge all surgeons to take advantage of the information it provides and we believe that as the technique becomes more widely used not only will its potential applications become more clearly defined but also other areas of usefulness will be identified.

ALAN J BRYAN BENICO BARZILAI

NICHOLAS T KOUCHOUKOS

Departments of Cardiothoracic Surgery and Cardiology,

Washington University Medical Center,

St Louis, Missouri, USA

$\ddagger$ Present address: Mr Alan J Bryan, FRCS, Department of Cardiac Surgery Bristol Royal Infirmary Bristol BS2 8HW.

1 Schluter M, Langenstein BA, Polster J, Kremer P, Souquet J, Engel S et al. Transoesophageal cross-sectional echocardiography with a phased et al. Transoesophageal cross-sectional echocardiography with a phased array transducer syst

2 Roelandt JRTC, Sutherland GR. Oesophageal echocardiography. $B r$ Heart $\mathcal{F}$ 1988;60:1-3

3 Matsuzaki M, Toma Y, Kusukawa R. Clinical applications of transesophageal echocardiography. Circulation 1990;82(suppl III):709-22.

4 Fisher HA, Stahl JA, Budd JH, Goldman ME. Transesophageal echocardiography: Procedures and clinical application. $\mathcal{f} \mathrm{Am}$ Coll Cardiol 1991;18:1333-48.

5 Lazar HL, Plehn J. Intraoperative echocardiography. Ann Thorac Surg 1990;50:1010-8.

6 Weintraub R, Schiota R, Elkadi T, Goldrouski P, Zhang J, Rothman A et al. Transesophageal echocardiography in infants and children with congenital heart disease. Circulation 1992;86:711-22.

7 Topol EJ, Weiss JL, Guzmann PA, Dorsey-Lima S, Blanck TJJ, Humphrey LS. Immediate improvement of dysfunctional segments after coronary revascularization: detection by intraoperative transesophageal coronary revascularization: detection by intraoperative

8 Koolen JJ, Visser CA, van Wezel HB, Meyne NG, Dunning AJ. Influence of coronary artery bypass surgery on regional left ventricular wall of coronary artery bypass surgery on regional left ventricular wall motion: an intraoperative two dimensional transesop

9 Hines RL. Transesophageal echocardiography: is it for everyone? $\mathcal{f}$ Cardiac Surg 1990;5(suppl):240-3.
10 Gorcsan III J, Diana P, Ball BA, Hattler BG. Intraoperative determination of cardiac output by transesophageal continuous wave Doppler. Am Heart $¥$ 1992;123:171-6.

11 Topol EJ, Humphrey LS, Borkon AM, Baumgartner WA, Dorsey DL, Reitz BA, et al. Value of intraoperative left ventricular microbubbles detected by transesophageal two-dimensional echocardiography in predicting neurologic outcome after cardiac operations. Am $\mathcal{f}$ Cardiol 1985;56:773-5.

12 Oka Y, Inoue T, Hong Y, Sisto DA, Strom JA, Frater RWM. Retained intracardiac air. Transesophageal echocardiography for definition of incidence and monitoring removal by improved techniques. 7 Thorac Cardiovasc Surg 1986;91:329-37.

13 Shaw PJ, Bates D, Cartlidge NEF, et al. Neurological complications of coronary artery bypass graft surgery: six month follow up study. $B M F$ 1986;293:774-82.

14 Orihashi K, Sisto DA. Intra aortic balloon pumping. In: Oka Y, Goldiner PL, eds. Transesophageal echocardiography. Philadelphia: JB Lippincott, 1992;301-11.

15 Reichert SLA, Visser CA, Koolen JJ, vd Brink RBA, van Wezel HB, Meyne NG, et al. Transesophageal echocardiography in hypotensive patients after cardiac operations. Comparison with hemodynamic parameters. F Thorac Cardiovasc Surg 1992;104:321-6.

16 Davila-Roman VG, Barzilai B, Eaton M, Wareing TH, Kouchoukos NT. Early postoperative complications detected by transesophageal echocardiography in cardiothoracic surgery patients [abstract]. $\mathrm{F} \mathrm{Am}$ Coll Cardiol 1990;15:130.

17 Simpson IA, Munsch C, Smith EEJ, Parker DJ. Pericardial haemorrhage causing right atrial compression after cardiac surgery: Role of transoesophageal echocardiography. Br Heart f 1991;65:355-6.

18 Brack M, Olson JD, Pedersen WR, Goldenberg IF, Gobel FL, Pritzker MR, et al. Transesophageal echocardiography in patients with mechanical circulatory assistance. Ann Thorac Surg 1991;52:1306-9.

19 Barzilai B, Davila-Roman VG, Eaton M, Rosenbloom M, Spray TL, Wareing TH, et al. Transesophageal echocardiography predicts successful withdrawal of ventricular assist devices. $\mathcal{f}$ Thorac Cardiovasc Surg 1992;104:1410-6.

20 Davila-Roman VG, Barzilai B, Wareing TH, Murphy SF, Kouchoukos NT. Intraoperative ultrasonographic evaluation of the ascending aorta in 100 consecutive patients undergoing cardiac surgery. Circulation 1991;84(suppl III):47-53.

21 Katz ES, Tunick PA, Rusinek H, Ribakove G, Spencer FC, Kronzon I. Protruding aortic atheromas predict stroke in elderly patients undergoing cardiopulmonary bypass: experience with intraoperative transesophageal echocardiography. $₹ \mathrm{Am}$ Coll Cardiol 1992;20:70-7.

22 Ribakove GH, Katz ES, Galloway AC, Grossi EA, Esposito RA, Baumann FG, et al. Surgical implications of transesophageal echocardiography to grade the atheromatous aortic arch. Ann Thorac Surg diography to grade.

23 Wareing TH, Davila-Roman VG, Barzilai B, Murphy SF, Kouchoukos NT. Management of the severely atherosclerotic ascending aorta during cardiac operations. A strategy fo

24 Phillips KJ, Davila-Roman VG, Barzilai B, Wareing TH, Daily BB, Davila $\mathrm{RM}$. Atherosclerosis of the ascending aorta: Intraoperative comparison of two ultrasound techniques to assess its severity [abstract]. $\mathcal{F} \mathrm{Am}$ Coll Cardiol 1993;21:342.

25 Erbel R, Engberding R, David W, Roelandt JRC, Visser C, Rennollet H. European Cooperative Study Group for Echocardiography: Echocardiography in diagnosis of aortic dissection. Lancet 1989;1: 457-60.

26 Adachi H, Omoto R, Kyo S, Matsumara M, Kimura S, Takamoto S, et al. Emergency surgical intervention of acute aortic dissection with the rapid diagnosis by transesophageal echocardiography. Circulation 1991;86 (suppl III): 14 - 9 .

27 Pinto FJ, Bolger AF. Doppler echocardiographic diagnostic advances in aortic dissection using transesophageal and intraoperative epicardial aortic dissection using transesophageal and intraopera

28 Tingleff J, Arendup H, Petterson G. Surgical repair of a postendocarditis abscess cavity in the heart guided by intraoperative transesophageal echocardiography. Eur f Cardiothorac Surg 1992;6:106-7.

29 Karalis DG, Bansal RC, Hauck AJ, Ross Jr J, Applegate PM, Jutzy KR, et al. Transesophageal Echocardiographic recognition of subaortic complications in aortic valve endocarditis. Clinical and surgical implications. Circulation 1992;86:353-62.

30 Kouchoukos NT, Davila-Roman VG, Spray TL, Murphy SF, Perrillo JB. Replacement of the aortic root with a pulmonary autograft in children and young adults with aortic valve disease. $N$ Engl f Med 1994;330:1-6.

31 Reichert SLA, Visser CA, Moulijn AC, Suttorp MJ, vd Brink RBA, Koolen JJ, et al. Intraoperative transesophageal color coded Doppler echocardiography for evaluation of residual regurgitation after mitral valve repair. $\mathcal{F}$ Thorac Cardiovasc Surg 1990;100:756-61.

32 Sheikh KH, De Bruiin NP, Rankin IS, Clements FM, Stanley T, Wolfe WG, et al. The utility of transesophageal echocardiography and Doppler color flow imaging in patients undergoing cardiac valve surgery. $\mathcal{f} \mathrm{Am}$ Coll Cardiol 1990;15:363-72.

33 Sheikh KH, Bengtson JR, Rankin JS, De Bruijn NP, Kisslo J Intraoperative transesophageal Doppler color flow imaging used to guide patient selection and operative treatment of ischemic mitral regurgitation. Circulation 1991;84:594-604

34 Freeman WK, Schaff HV, Khanderia BK, Oh JK, Orzulak TA, Abel MD et al. Intraoperative evaluation of mitral valve regurgitation and repai by transesophageal echocardiography: Incidence and significance of systolic anterior motion. $\mathcal{A}$ Am Coll Cardiol 1992;20:599-609.

35 Grigg, LE, Wigle D, Williams WG, Daniel LB, Rakowski M Transesophageal Doppler echocardiography in obstructive hypertrophic cardiomyopathy: Clarification of pathophysiology and importance in intraoperative decision making. $¥ \mathrm{Am}$ Coll Cardiol 1992;20:42-52

36 Marwick JH, Stewart WJ, Lever HM, Lytle BW, Rosenkranz ER, Duffy CI, et al. Benefits of intraoperative echocardiography in the surgical management of hypertrophic cardiomyopathy. $\mathcal{f}$ Am Coll Cardio 1992;20:1066-72.

37 Cope EG, Jaarsma W, Yoganathan AP. Echo Doppler principles, techniques, and applications for the cardiac surgeon. Eur $\mathcal{F}$ Cardiothorac Surg 1992;6(suppl 1):2-12. 